\title{
GEODESIC SANDWICH THEOREM WITH AN APPLICATION
}

\author{
Absos Ali Shaikh, Ravi P. Agarwal and Chandan Kumar Mondal
}

Abstract. The main goal of the paper is to prove the sandwich theorem for geodesic convex functions in a complete Riemannian manifold. Then by using this theorem we have proved an inequality in a manifold with bounded sectional curvature. Finally, we have shown that the gradient of a convex function is orthogonal to the tangent vector at some point of any geodesic.

Mathematics subject classification (2010): 26B25, 39B62, 52A20, 52A30, 52A41, 53C22.

Keywords and phrases: Convex functions, sandwich theorem, gradient of convex functions, separating convex functions.

\section{REFERENCES}

[1] D. AZAgra, J. Ferrera, AND F. Lopez-Mesas, Nonsmooth analysis and Hamilton-Jacobi equations on Riemannian manifolds, J. Funct. Anal., 220, 2 (2005), 304-361.

[2] K. Baron, J. Matkowski, And K. Nikodem, A sandwich with convexity, Math. Pannonica, 5, 2 (1994), 139-144.

[3] R. L. Bishop, AND B. O’Neill, Manifolds of negative curvature, Trans. Amer. Math. Soc., 145 (1969), 1-49.

[4] F. C. Mitroi-Symeonidis, A sandwich theorem for convex set valued functions, An. Univ. Oradea Fasc. Mat., 1 (2016), 77-79.

[5] R. E. GREENE, AND H. WU. H., On the subharmonicity and plurisubharmonicity of a geodesic convex function, Indiana Univ. Math. J., 22, 7 (1973), 641-653.

[6] A. IQbal, I. Ahmad, AND S. Ali, S. Some properties of geodesic semi-E-convex functions, Nonlinear Anal., 74, 17 (2011), 6805-6813.

[7] A. IQBal, S. Ali, AND I. Ahmad, I., On geodesic E-convex sets, geodesic E-convex functions and E-epigraphs, J. Optim. Theory Appl., 155, 1 (2012), 239-251.

[8] J. Jost, Riemannian geometry and geometric analysis, Springer, Berlin, 2011.

[9] T. Lara, J. Matkowski, N. Merentes, And R. Quintero, A Generalization of m-Convexity and a Sandwich Theorem, Ann. Math. Sil., 31, 1 (2017), 107-126.

[10] J. Matkows Ki, AND M. WròBel, Sandwich theorem for m-convex functions, J. Math. Anal. Appl., 451 (2017), 924-930.

[11] K. NiKODEM, AND S. WASOWICZ, A sandwich theorem and Hyers-Ulam stability of affine functions, Aequationes Math., 49, 1 (1995), 160-164.

[12] T. RAPCSAK, Smooth nonlinear optimization in $\mathbb{R}^{n}$, Kluwer Academic Publisher, 1997.

[13] R. Schoen, And S. T. YAu, Lectures on differential geometry. Conference Proceedings and Lecture Notes in Geometry and Topology, I. International Press, Cambridge, MA, 1994.

[14] A. A. Shaikh, A. IQBaL, AND C. K. Mondal, Some results on $\varphi$-convex functions and geodesic $\varphi$-convex functions, Differ. Geom. Dyn. Syst. 20 (2018), 159-170.

[15] C. UdRIŞTE, Convex functions and optimization methods on Riemannian manifolds, Kluwer Academic Publisher, 1994. 